\title{
The Rhetorical Structure of Argumentative Discourse as Expressed in Israeli Supreme Court Verdicts
}

\author{
Orly Kayam
}

The Zinman College of Physical Education \& Sport Sciences at the Wingate Institute Ltd, Israel

Email: Orlyka@wincol.ac.il

Received:November 01, 2012 Accepted:December 13, 2012 DOI:10.5296/jpag.v2i4.2618

\begin{abstract}
The aim of this article is to present and discuss the role and function of structure in argumentative discourse as expressed in Israeli Supreme Court Verdicts with a review of the literature from ancient Greece to modern times. This article includes a presentation of both Brewer's and Roe's models of text classification and presents the four types of text according to the classic classification, focusing primarily on the argumentative-persuasive text with particular attention to its unique rhetorical structure. The rhetorical structure of a text has crucial importance because it enables one to see an aspect of the rhetorical analysis. Graphic representation of the rhetorical structure of argumentative discourse by means of flowcharts is also discussed and examples are presented in the appendix to this article.
\end{abstract}

Keywords: Rhetoric, Structure, Argumentative Discourse 


\section{Introduction}

The study of rhetoric is a broad field that encompasses hundreds of devices. In my previous articles I have addressed the use of rhetorical devices in fields as disparate as the writing of Supreme Court verdicts and sports commentary ${ }^{1}$. This article addresses the rhetorical structure of argumentative discourse as expressed in Israeli Supreme Court verdicts and presents a survey of the literature on the subject of rhetorical structure from ancient Greece to modern times.

\section{Theoretical Background}

From Aristotle the research literature ${ }^{2}$ has divided texts into the following four categories: narrative text, descriptive text, expository text and argumentative or persuasive text. Saral (1991) states that there are fundamental shortcomings to this classic classification ${ }^{3}$ that hamper research. Discourse researchers (e.g. Van Dijk, 1980) have attempted to improve it in order to contend with a wide variety of texts that were previously outside the domain of linguistic study. They created "grammatical texts" to expose the rules that are the foundation of all forms of text by examining the characteristics of the different texts. They showed that each form has its own organizational principles, that is, a specific rhetorical structure and different focus in the text. An additional way to improve the classical model and aid research is by presenting more complex models, for example, two-dimensional models that classify discourse types by two different measures.

Brewer's model (1980) divides texts according to the following two measures:

(a) Structure, including three different types of discourse and their identifying marks in the superstructure that organizes the type of discourse and hints at the structure of the foundation.

(b) Purpose, represents the reciprocal interaction between the writer's intent and the reader's comprehension of the message.

Roe's model (Roe et. al., 1978) divides texts according to the following two measures:

(a) Organization, how the text is organized around different points of focus

(b) Structure, which includes different ways of developing the writer's ideas.

$1 \quad$ Kayam, 2012; Kayam and Galily, 2012; Kayam and Kaufman, 2011.

2 For example, Connolly, 1953; Kinneavy, 1971; Brooks and Warren, 1972; Brewer, 1980; Van Dijk, 1980; Fox, 1986 and others.

3 (a)This method of classification does not relate to practical texts, whose basic rules differ from those of the four types of texts mentioned.

(b) The classification is based primarily on intuition with little regard for objective criteria that can be examined and verified. 


\section{Macrothink}

This article will present the four types of text according to the classic classification focusing primarily on the argumentative-persuasive text with particular attention to its unique rhetorical structure. The rhetorical structure of a text has crucial importance because it enables one to see an aspect of the rhetorical analysis.

\section{Classic Classification}

\subsection{Narrative Text}

Saral (1991) writes that the narrative text is divided into sub-groups: the short story, the novel, the parable, the folktale, and so on. The short story is the most common and the most typical. Researchers ${ }^{4}$ characterize the short story as a series of events that take place around or by a character or characters in a set period of time and the action is the focus of the events. The short story has its own rhetorical structure, that is, a form of organization of the communication functions of the text. The rhetorical structure of the typical short story is composed of two parts: the presentation, which describes the starting point, the time and place of the event and presents the central characters and any additional necessary background information etc.; and the episode, which is generally divided into two parts entanglement and resolution. A multiplicity of verbs, mostly action or stative verbs is a characteristic linguistic form of the short story.

\subsection{Descriptive Text}

Researchers ${ }^{5}$ state that the aim of the descriptive text is to present that which can be perceived by the senses. This category is divided into two sub-groups: (1) the useful-practical description, the most common in all areas of life, and its primary characteristic is the presentation of facts in referential language given to repetition and "photographic", that is, experienced as a photograph; (2) artistic description, directed to the senses using figurative speech that deliberately influences the senses. Descriptive text appears primarily in fine literature in descriptions of landscapes, portraits, background and the like. A multiplicity of adjectives and minimal use of verbs characterize this linguistic form.

\subsection{Expository Text}

Connolly (1953) states that the aim of expository text is to present people, facts and ideas; to explain historical events and social phenomena; to clarify political opinions; to test findings and evidence in different domains, that is, to explain all that is in need of explanation and clarification. Saral (1991) points out that the focus of the discourse is generally the central idea, surrounded by supporting details. Relaying the information, the ideas and opinions, is factual and this is the difference between it and argumentative discourse. This text is very common and very important in the field of educational texts, in students' writing and reading

4 De-Beaugrande and Dressler, 1981, p. 184; Brewer, 1980, p.222; Connolly, 1953, p. 311: Fox, 1986, p.25; Brooke and Warren, 1972, chapter 9. 
materials. Its rhetorical structure is divided into two main axes that include additional rhetorical sub-categories, which from a textual-status stand are secondary: the central idea, which divides into generalization and details; the evidence, which divides into clarification and demonstration. A multiplicity of objective adjectives, a multiplicity of static verbs and a multiplicity of nominal sentences characterize this type of text from a linguistic standpoint.

\subsection{Argumentative or Persuasive Text ${ }^{6}$}

The aim of the argumentative or persuasive text is to convince, to garner support for a specific opinion or belief or to spur the listener to take action of some kind. Azer (1998) defines argumentative text as text or a part of a wider text, that has an argumentative relationship, which is defined as the relationship that exists between two parts of a text: the one - that expresses a position on an issue in dispute; the other - that aims to convince the reader to adopt that position to some extent or another, and to change his belief or behavior accordingly. Saral (1991) states that the characteristics of the argumentative text are substantiation and evidence using the formulas of logic to compare axioms: " $\mathrm{A}=\mathrm{C}$ because $\mathrm{A}=\mathrm{B}$ and $\mathrm{B}=\mathrm{C}$ ". The text is also characterized by limitations, reservations and argument.

The researchers attach great importance to the organization and structure of the presentation of the arguments. Bryant (1976) states that the speaker shall organize his arguments in accordance with his perception of the importance of their message according to his audience. The speaker shall use the organizational techniques of structure, which are meant to emphasize this or that aspect of the discourse. The arguments, which are related, will emphasize the idea which the speaker considers important. For example: The speaker presents his arguments in a rational logical manner using the technique of presenting opposing arguments, convincing his listeners that there is a special importance to the differences between the opposing arguments. The confrontation and opposition will highlight and sharpen the differences between the arguments. Bryant (1976) states that a persuasive speech must have appropriate structure and organization. Organization of the material and proper structure of the presentation of the arguments are factors that can influence the listeners' positions. Logical organization of the arguments, for example, influences good understanding of the message. A logical organization of a speech expresses the logical relationship among its parts: cause and effect; argument presentation and explanation; the logical development of the topic, such that one idea leads to the next, and the entire text becomes a single unit with one subject and meaning.

Brooks and Warren (1970) state that refuting opposing arguments helps the listener to think logically, to identify mistaken arguments and to understand the weaknesses of the opposing arguments.

$6 \quad$ Kinneavy, 1971; Nir, 1984 and others saw argumentative discourse as distinct from persuasive discourse and not as synonyms for the same type, as was Saral (1991) practice. Azer (1998), argues that argumentative text is sometimes persuasive text, but that not all persuasive text is argumentative: there must be at least one sentence whose role is to support the expressed position for it to be considered argumentative. 
Hughes and Duhamel (1962) present principles of effective organization of text, and argue that comparison between arguments that are agreed upon allow better understanding of the message than comparison between arguments upon with there is no agreement.

Perlman (1984) is of the opinion that when raising arguments meant to achieve the audience's agreement, it is of crucial importance to organize the order of the arguments.

Kinneavy (1971) also attributes great importance to the organization of the persuasive discourse, and reviews the subject thoroughly and at length. Organizing persuasive discourse refers to the structure of the parts of the speech that appear as spoken or written text. According to him the rhetorical tradition is very clear on this topic: The assumption was that every serious rhetorical speech contains the following parts: Introduction (presentation of the topic); Story (the circumstances of the story); Proposal (the speaker's position); Points of Conflict (the points that the speaker intends to prove); Confirmation (the body of proof); Rebuttal (refuting the opponent's arguments); Summary (review and appeal to emotion).

Socrates and rhetoricians that preceded Aristotle presented only four parts: Introduction, Story, Confirmation and Summary. Aristotle argued that only two sections were critical: the argument and the proof (i.e. the proposal and the confirmation). All the rest depends on the subject and the audience. As we shall see further on these four divisions are similar to a great extent with the four sections that compose the verdicts of the Israeli Supreme Court.

Latin rhetoricians (Gitay, 1991, chapter 2) added to this and argued that there are six divisions: Introduction; Presentation of the facts; Declaration of what will be addressed; Proof; Rebuttal; Summary.

Modern rhetoricians included these structures and created persuasive templates that matched, to a certain extent, the traditional ones with some exceptions regarding their order: basic rhetorical templates include classic rhetorical models that are composed of: Question, Argument, Reason, Demonstration and Conclusion. A broader classical rhetorical model includes: Preface, Definition of the problem, Resolution, Reasoning, Rebuttal of opposing arguments, Summary and Conclusion.

Reboul (1984) presented four stages of rhetorical discourse: Invention; Order, which includes Introduction, Description, Proof and Summary; the Art of Speech; Speech Execution, that is, the act of giving the speech.

Brooks and Heath (1985) presented a persuasion template that opened with a presentation of the problem, followed by the presentation of a solution, reasoning, demonstration and a call to action.

Perlman (1984) writes that arguments can be organized in one of three ways based on the strength of the arguments: the strength of the argument gets stronger and stronger; the strength gets weaker and weaker; opening and closing with strong arguments and leaving the rest of the arguments in the middle. Perlman reviewed the strengths and weaknesses of each method and wrote that the organization of arguments is not set but changes in accordance with the audience of listeners. 
Malchin (1990) presented a rhetorical model that included the following: the topic as a question; the argument as an answer; definition of key concepts; reasoning; demonstration; conclusion and recommendation.

\section{The Rhetorical Structure of Argumentative Discourse}

The most widespread expression of rhetorical structure of argumentative discourse has a clear binary dual-axis structure described by Van Dijk and Saral ${ }^{7}$ as follows: The main axis has two categories: 1) the argument and 2) the conclusion. These are the main categories. The secondary axis includes different sub-categories that derive from the main argument: 3) premise, 4) data, 5) rebuttal, 6) justification, 7) setting, 8) backing. These sub-categories are of secondary importance and their role is to support the main argument and lead to the conclusion.

1. The argument is a central statement that expresses a certain position of the speaker that requires support in the form of substantiation, explanation, evidence and so on in order to be convincing and to generate support for said position. $^{8}$

Blum (1978) writes that argument is a series of inferred statements, where one statement is the conclusion of the argument and all the other statements, if there are any, are a preface to the argument. Accordingly, an argument can have any number of prefaces including zero, but only one conclusion. Normally a preface to an argument is used to justify the conclusion. Copi (1982) states that there are different types of arguments: deductive arguments (an argument whose prefaces are meant to provide compelling evidence of the veracity of the conclusion); inferred arguments (an argument where the conclusion is derived from two prefaces, there are different types of this type of argument); inductive argument (an argument that doesn't pretend to proof the veracity of its conclusion, that necessarily derives from its prefaces, rather only that its veracity is reasonable, logical or probable). Copi (1982) says that the argument is the starting and ending point of the process of inferring. Also Antaki (1994) ${ }^{9}$ writes that a statement is an argument if it can be debated, that is, it needs to be proved. Likewise its rhetorical structure hints at its nature in that after the argument some form of justification is necessary, and at the end of the process there is generally a repetition of the argument in a closing of the circle. There is a process here that starts at a given point, followed by postulations or statements that try to lead to a conclusion. Acceptance of the

7 There are some differences between the analysis of Van Dijk and Saral which are expressed in different ordering of the categories seen in the diagram. There are also differences in terminology: Van Dijk terms "premise" the same category that Saral terms "argument", and Van Dijk doesn't refer to "rebuttal" which is mentioned by Saral.

8 This definition, based on various books of rhetoric, is mine. I chose it because it best represents the same category in the texts that I have analyzed. 
conclusion requires acceptance of the starting point (that is the argument).

Shilo (1996), examining argumentative texts in the press, found that there are different techniques for writing an argument: explicitly; in a very general manner; as a rhetorical question; implicit from the opposition. Saral (1991) also comments that it is not always possible to identify the central argument as an explicitly worded statement: sometimes it will appear only in the infrastructure and it is up to the reader to infer the meaning from the statements.

2. The conclusion is derived from the reasoning or justification of the argument. There are conclusions that derive necessarily from assumptions and present a clear convincing structure - these are deductive syllogisms. Likewise there are conclusions that are not necessarily derived from their assumptions, and they are presented in a manner more persuasive than convincing - these are inductive syllogisms. They are very common in texts that express opinions.

Copi (1982) argues that the conclusion can appear at the beginning, the end or the middle of an argument and thus it can be difficult to locate. It can be identified by the concluding words that precede it such as: accordingly, therefore, for this reason, indeed, from this, as a result of which, we can conclude, etc. When these types of words do not appear the context can help. Van Dijk (1980) writes that the conclusion may precede the argument in cases where an explanation is given for a specific fact.

Such a situation would assume prior knowledge on the part of the listener and would describe the causes that explain this knowledge.

Shilo (1996) discusses different types of summaries in argumentative texts taken from the press. She found different combinations of conclusions plus an additional element, such as: conclusion + recommendation; conclusion + recommendation + warning; summary + conclusion; forecast + conclusion.

Sub-categories on the secondary axis:

Premise: The function of the premise is to strengthen the central argument thus making it more convincing and tying the central argument to the rest of the categories. The clarity of the argument structure is seen mainly in the expression of the premise. Premises include words like: "I declare that..."; "I promise that..."; "I predict..."; and so on. Shilo (1996) assumes that there is no substantial difference between the argument and the premise and that there is no guarantee that said premise will in fact appear.

Data: Data includes descriptions or conclusions regarding the situation or events that the speaker perceives as true, and are acceptable to the listener. If the data includes information that is not accepted directly, then there may be a hidden argument or at least a clarification of the information. The data generally follow the premise and often include words like: "Inasmuch as..."; "Because..."; and so on. 
On occasion there are an additional two sub-categories that branch out from the premise and they are:

Rebuttal: The function of the rebuttal is to strengthen the credibility of the argument or the premise and sometime the data to the listener. Theoretically the rebuttal weakens the credibility of the above categories but this is only temporary because in the end the other categories are strengthened by the rebuttal because presenting the other side shows that the speaker is not afraid to deal with opposition to his positions and this strengthens his credibility.

Justification: The justification comes after the rebuttal and clarifies the connection between the argument and the data ${ }^{10}$. In order to draw conclusions from specific facts an argument must have a more general assumption in regards to the relationship between the different facts in the form of justification ${ }^{11}$. Sub-categories of justification are generally evident in the model of "if...then...". The justification following the rebuttal, is a response to the rebuttal, and thus strengthens the argument, as well as a response to potential rebuttals and brings them to an end.

The justification generally opens with the words: "But..."; "However...."; "Nevertheless..." and so on.

Sub-categories of the justification and the rebuttal constitute another axis, secondary in importance to the axis that preceded it.

Additional sub-categories liable to be added are:

Setting: Presents the background and related factors to the problem or topic. Shilo (1996) says that the function of the setting is to lead to the written argument. The setting does not appear in the form of an argument but rather as a description of facts, events, emotions, and so on. He found that the setting in argumentative texts in the press appeared in a number of manners: as descriptions of events or of facts that led to events; quotes that constituted the basis for the argument; a combination of description of events + quotes; description of feeling that leads to presentation of an argument; the clarification or definition of a concept. In the legal texts analyzed for this article setting was found to be essential and to include factual background, normative background and sometimes, when necessary, legal background.

Backing: The backing is based on the premise and supports the justification. Often the backing will appear as a quote relying on a single source as in the example: "Judge Cohen also recommended..."or "Supreme Court verdict 606/93 also ruled" and so on.

Saral (1991) remarks that these sub-categories are optional because in some of the cases they are either known to the listener or are implicitly self-evident. Van Dijk (1980) writes that there are some sub-categories that remain implied because they are based on general

10 See Weizman (2000)

$11 \quad$ Van Dijk, ibid. 
knowledge which due to pragmatic reasons do not need to be mentioned in the informal media.

Additional sub-categories, found in legal texts are:

Question-Driven Discussion $^{12}$ : This is a question contained in the subject which organizes the thinking and advances the discussion. It is essential to the focus and direction of the argument, it identifies the topics to be addressed, their limits, and the goals to be achieved. Without it, says Malchin (1990), the argument wanders in a maze of the many questions on the subject. The question will not always appear explicitly but can be inferred from the infrastructure of the argumentative text. In court verdicts the question is generally stated in a clear and precise manner at the beginning of the text and is therefore easy to identify.

Other Arguments ${ }^{13}$ and their Refutation: This is an optional sub-category in which the speaker presents and argues the opposing position with the intent of invalidating it. He may show the inconsistencies, the lack of logic, or its detachment from reality and so forth. ${ }^{14}$ Researchers are divided over the question of the necessity of the refutation. Aristotle, for example, believed it not necessary but Quintilian did not agree and saw the ignoring of one's opponent's argument as a weakness in one's own argument. Bryant (1974) states that it is incumbent upon the speaker not only to explain and prove his own argument but also to fairly present the opposing views.

"Other arguments" in court verdicts are likely to be the petitioner's arguments, the defendant's arguments, or the arguments of other judges on the case. Uses of this sub-category in the texts analyzed for this paper were many and varied. For example, the petitioner's arguments can be presented at the end and immediately refuted or in the beginning and the whole verdict was devoted to their refutation. In other cases an entire verdict can be composed of the petitioner's arguments or the arguments of another judge who sat on the case ${ }^{15}$ with a refutation alongside each argument such that all the conclusions will lead to the final conclusion.

\subsection{A Graphic Presentation of the Rhetorical Structure of Argumentative Discourse}

One of the ways to illustrate the structure of texts of the same register is by way of a flowchart. Abadi (1984) discusses the use of graphics to expose the structure of written text. She writes (1984) that to discover the structure and shape of written text, one must consider

12 See Malchin, (1990)

13 I use the term "other arguments" and not "opposing arguments", as is customary in argumentative discourse, because in court verdicts it would not be correct to term the arguments made by the petitioner as “opposing arguments".

14 See Bryant (1974) and Connolly (1953).

15 Unlike the American court system, in Israel a panel of three, five, or seven judges hears a case. 
its graphic division, and also examine the internal structure of the text, through the relationship between its components.

Horovitz (1999) also believes that transferring the written text to graphic text aids in identifying the structure and organizing its content, that is, it adds understanding. She mentions significant advantages to the use of graphics ${ }^{16}$. She discusses the significant advantages of graphic presentation, ${ }^{17}$ and writes that the two-dimensional graphic depiction allows the full structure to be presented to the reader as well as the relationship between its components. and to neutralize the one-dimensional linear written text. The graphic depiction gives the reader an overall picture of the focus points of the text and their mutual organization. Hence the graphic depiction is necessary for understanding the text and grasping its structure and components.

Following Van Dijk et.al. (1980) Saral (1991) proposed a schematic model, shown below, of the rhetorical structure of argumentative discourse. The model, presented as a flowchart, illustrates the global rhetorical structure of argumentative discourse. This model is very important because it provides a "skeleton" for analyzing rhetorical structures. However it should be noted that this is only a general example and there may be variations. Saral (1991) says that the order of the categories is not constant. Van Dijk (1980) also explains that the order of the categories can change in certain cases. Kinneavy also relates to the order of the categories and raises the following question: What is the preferred order of a speech, is it preferable to start with the anti-climax (the argument) followed by the proofs, or the climax (the proofs) followed by the argument? While the research is inconclusive on this matter Kinneavy favors the latter in landmark cases that are familiar to the audience. The hierarchy of the axes is not affected by the order of the categories.

16 See also Greimas \& Nef (1977).

17 In the framework of a discussion on form and content of reading comprehension, ibid. pp. 171-172.

Though Horowitz writes from a pedagogical viewpoint that doesn't change the fact that these advantages are identical to that seen from a purely linguistic viewpoint. 
Figure 1. The Rhetorical Structure of Argumentative Discourse

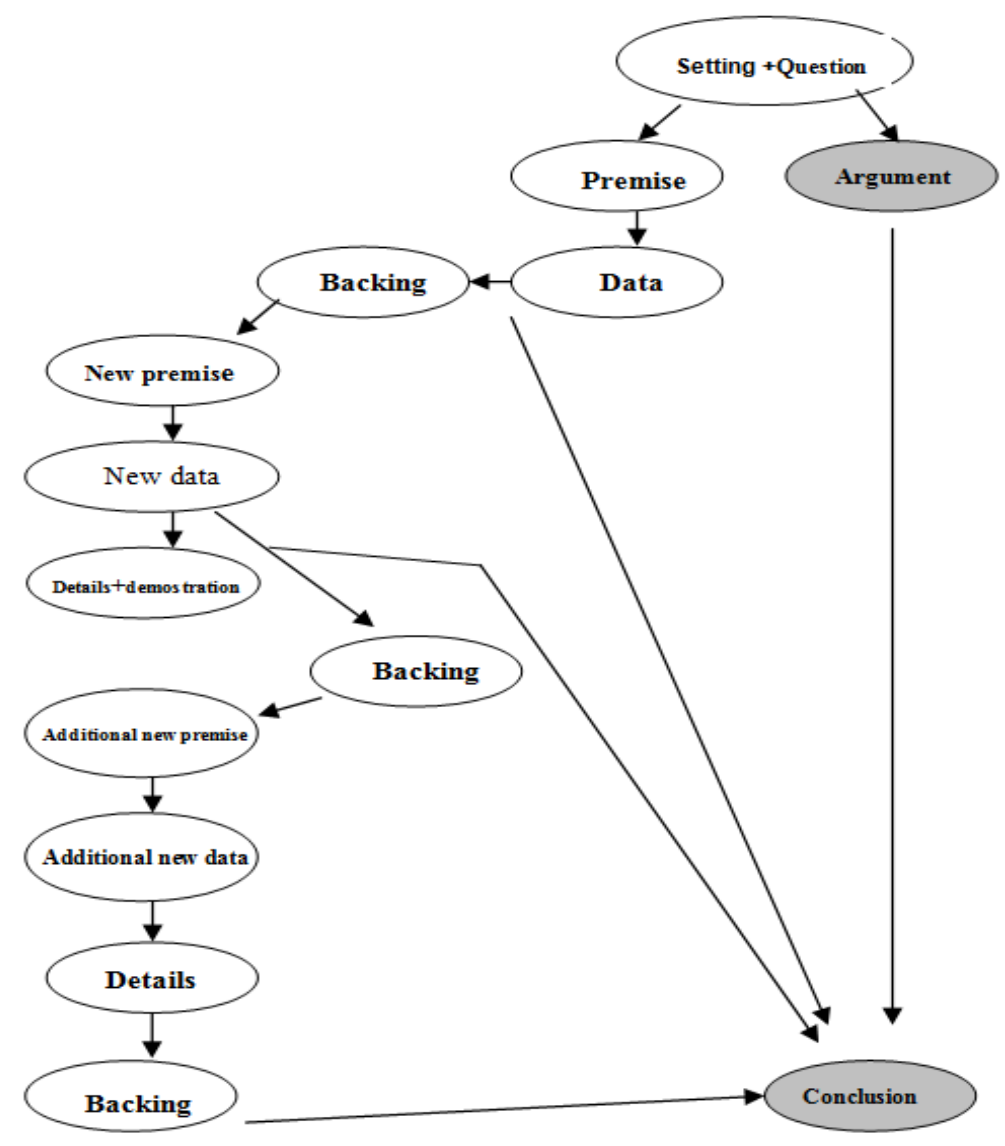

In this article the above model will be termed "the regular model" and where the categories are reversed will be termed "the inverted model".

\section{The Legal Structure of Israeli Supreme Court Verdicts}

Generally, verdicts are composed of four accepted parts described by Justice Dorner (in an interview at the Supreme Court on February 21.2.99). Part one is the factual background which includes the petition and the question that has been raised for discussion ${ }^{18}$. Part two is the normative infrastructure which includes the laws, precedents, and any other sources upon which the judge bases his verdict. Part three addresses the application of the law to the specific case and includes the judicial reasoning. Perlman (1984) says that judicial logic can be found in the courts' reasoning. This logic is guided by the judges' ideology, and by the way they view their function and their perception of the law and their worldview concerning their relationship with the legislature. He continues and says that the judicial conclusions in the modern period after 1945 is characterized by "topiques jurdiques", which means the considerations that the legislator and the judge must take into account in the process of formulating the law and its implementation. Gabizon (1970) says that the judges in additions 
to implementing existing laws must interpret the law in cases where they do not find a suitable law. The judges themselves attributed great importance to substantiating their decisions. This can be seen in those cases where the judges came to the same outcome but differed on the reasoning. In those cases the judges wrote separate verdicts which led to different legal conclusions (Gabizon, 1970). Justice Barak (1982) holds that the judge is the interpreter of the law. The law determines the norm and the judge determines its limits.

Justice Cheshin (ibid.) said: "The Supreme Court is authorized to deal with matters where there is a need for legal aid for the sake of justice." This derives not only from the law or its interpretation but from the principles of democracy and universal concepts of justice and so on. At the same time every court is authorized to do justice in accordance with the law and statutes. The Supreme Court may also do justice beyond the law and statutes and that justice becomes the common law. In public law "The pulse of justice" beats strong. Regular courts deal with clearly defined material, in accordance with ancient traditions, where the rules are generally known, but in the public or administrative law there is greater freedom and more room for considerations. This is first of all a very young field, there is no complicated net of reference that can be relied on. Cheshin in figurative language says "The field has not yet been deeply plowed." Secondly, this field is full of terms like: "human dignity", "injustice", "reasonableness", "in good faith", "arbitrariness", and so on. On these topics the formulas are "formulaic frames" whose content changes from period to period and from judge to judge. The concepts are very general and require broad consideration.

According to Levy (1968) the need for substantiation derives from the fact that it is not right that the law is an ensemble of known rules which are implemented by a judge in a given case. In reality these rules are hazy and maybe they can't be sharp and clear. Levi explains the stages of judicial reasoning: finding a suitable precedent, finding the legal rule that was used in the precedent, and the implementation of said rule on the current case. He also claims that the judge has broad freedom in his decision as to which facts are relevant and which are to be ignored.

Gavish (1988), comments that these stages described by Levi are not always fully covered. Verdicts in all their diversity indicate that judicial reasoning is conducted in many different ways above and beyond what is described above.

Justice Cheshin (Interview at the Israeli Supreme Court May 3, 1998) explains that in the initial stage of implementing a law there is an argument with oneself and intellectual coping. The judge must present his arguments and justify them. The judge must explain the logical basis of his arguments: "The judge does not and must not have an a priori opinion on any subject, only after examining the case, and hold only justice before his eyes."

This is the place to emphasize that we are addressing the law not from a judicial viewpoint but from a linguistic rhetorical point of view.

The fourth part is the conclusion which is derived from the previous parts and the factual background, from the normative infrastructure and the process of implementation of the law in this case. 


\section{Macrothink}

Cheshin says (ibid.) "The persuasiveness of the material before me and my rational, logical, intelligent intuition lead me to the conclusion."

Generally, says Justice Dorner ( Interview at the Israeli Supreme Court February 21, 1999), there is a clear separation between the four parts. However in complicated cases there may be an overlap of parts $\mathrm{B}$ and $\mathrm{C}$. This is in order to preserve the connection between the normative infrastructure and the case. The overlapping helps the reader follow the course of the proceedings.

From all the above we understand that the main effort of persuasion will take place in part $\mathrm{C}$ of the verdict. So we expect to find most of the categories of the rhetorical structure, which were explained above, in the third part of the verdict. In the analysis of the rhetorical linguistic structure of the verdicts most of it is done in part three. Hence there exists congruence between the judicial structure and the rhetorical structure and the fact is that most of the categories of the argumentative discourse are in the implementation of the law. A study of diagrams of the rhetorical structure of verdicts clearly shows the congruence: The factual and normative background is the basis for the implementation of the statutes. In this part there are no categories of the argumentative discourse. Implementation of the law derives from both of them. In this implementation are centered most of the categories from which are derived the fourth part, the conclusion, which is a category unto itself. An in-depth discussion of the rhetorical structure of legal verdicts can be found in my book On the Scales of Justice [in Hebrew] where I address the rhetorical structure of six verdicts where each represents a different rhetorical structure. The graphic representation of those structures is provided in the appendix to this article. 


\section{Appendix}

Figure 2: The Rhetorical Structure Of Supreme Court Ruling 33/92 The Ben- Yosef Verdict

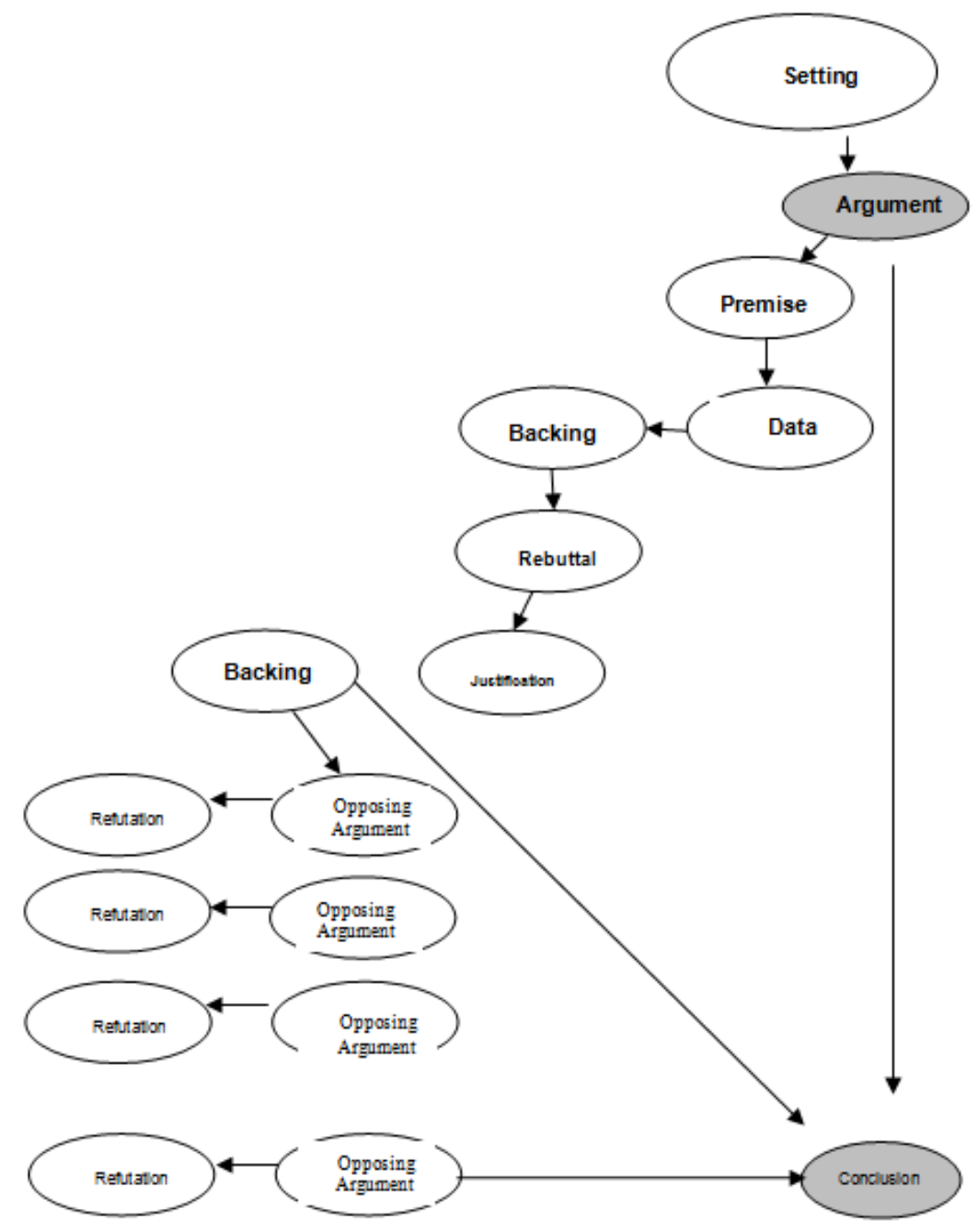


Figure 3. The Rhetorical Structure of Supreme Court Ruling 56/68 The Shalit Verdict

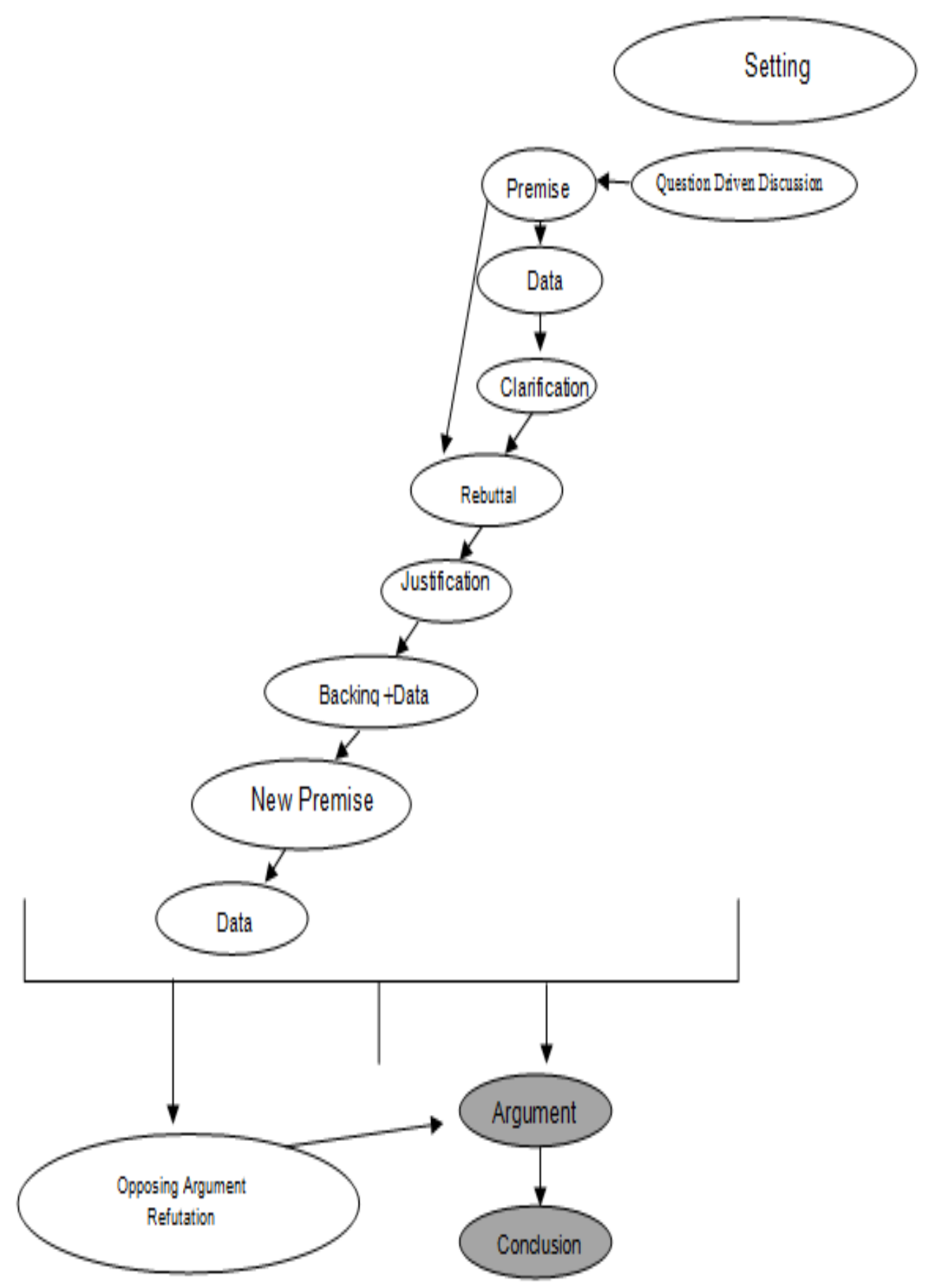




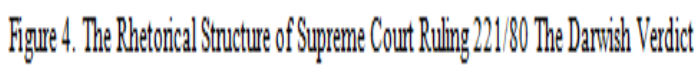

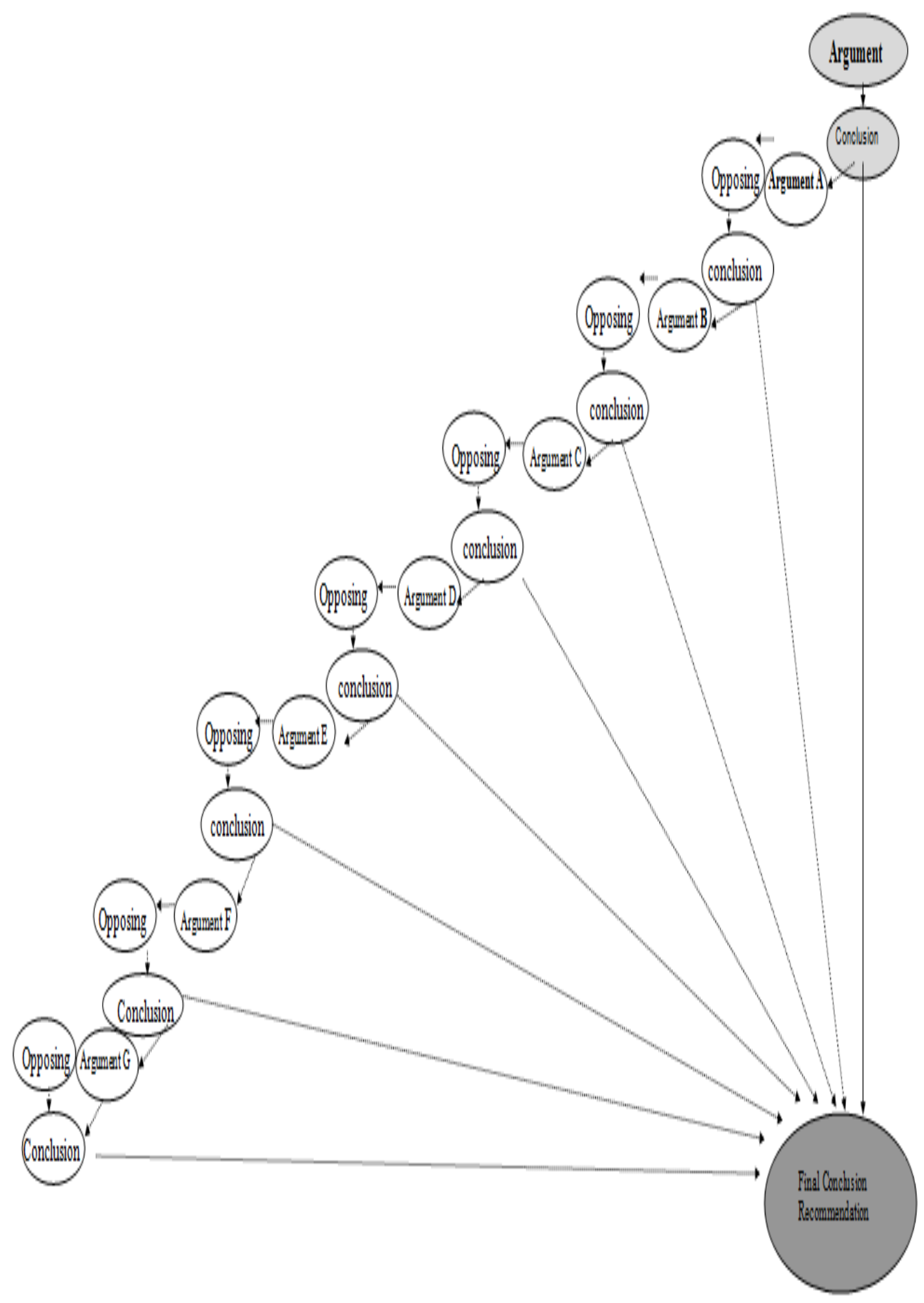


Figure 5. The Rhetonical Structure of Supreme Court Ruling 606/93 The Kidum Verdict

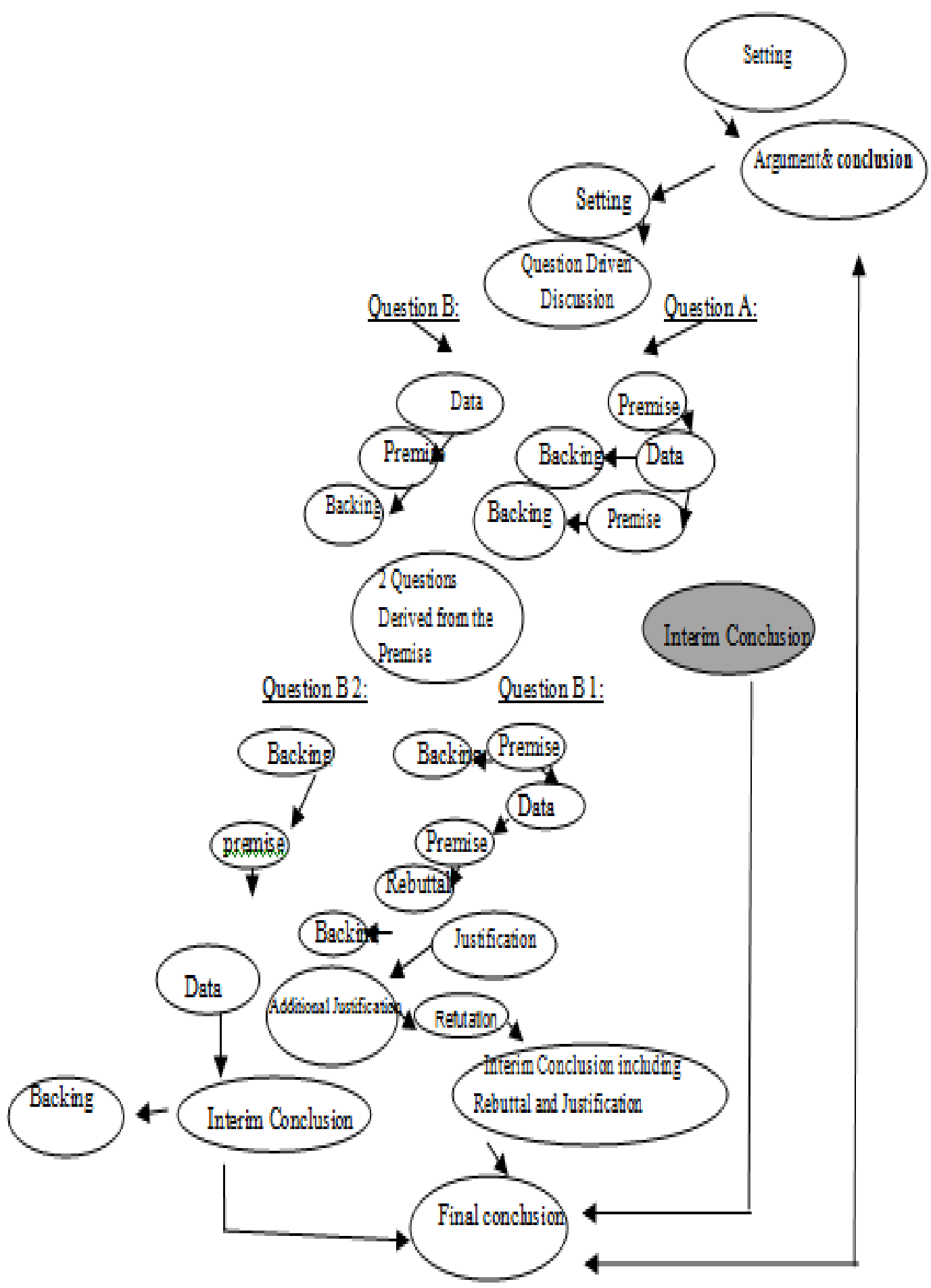




\section{Macrothink

Figure 6. Rhetorical Structure of Justice Or's Verdict

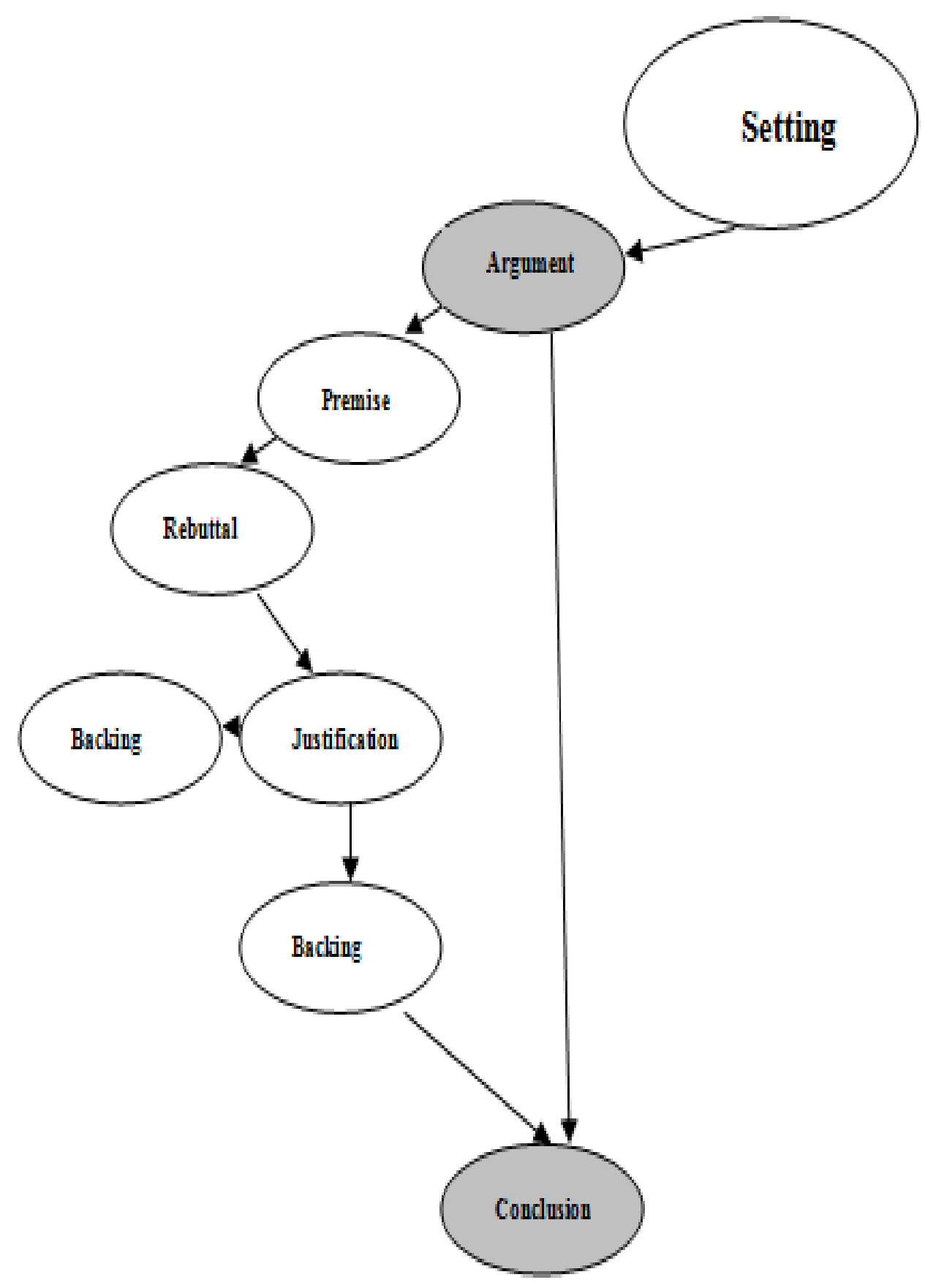




\section{Bibliography}

Abadi, A. (1984), Characteristics of Coherencyin Written Hebrew Discourse, [in Hebrew], $\mathrm{PhD}$ dissertation Bar-Ilan University, Ramat Gan.

Antaki, C. (1994), Explaining and Arguing, London, Sage Publications.

Aristotle, (1954), Rhetoric and Poetics, Vol XI, Clarendon press, Oxford.

Aristotle, (1932), The Rhetoric, (Trans. Lane Cooper) Englewood Cliffs: Prentice-Hall, New-York.

Azer, M. (1998), "Argumentative Text - Its Substance and Characteristics", Lecture [in Hebrew] at the Israeli Applied Linguistics Conference at the Haifa University

Barak, A. (1982), Judicial Judgement, [in Hebrew], Tel Aviv Univer

sity: Papirus Press.

Blum, A. (1978), Logic, Tel Aviv: Dekel Publishe.

Brewer, W. F. (1980), "Literary theory, rhetoric and stylistics: implications for psychology". In R. J. Spiro, B. C. Bruce, \& W. F. (Eds.), Theoretical issues in reading comprehension, Hillsdale, New Jersey: Erlbaum. pp. 221-244.

Brooks, W. D. \& Heath, R. W. (1985), Speech Communication, Dobuque, Iowa, W. C. Brown Publishers.

Brooks, C. \& Warren, R. (1970), Modern Rhetoric, USA, Harcourt Brace and World Inc.

Bryant, D. C. (1974), Fundamentals of Public Speaking, New York, D. Appleton Century.

Connolly, F. (1953), A Rhetoric Case Book, New York, Harcourt, Brace Company.

Copi, I. M. (1982), Introduction to Logic (6 ${ }^{\text {th }}$ edition), New York:Macmillan Publishing Co., Inc.

De-Beaugrande, R. A.. \& Dressler, W. (1981), Introduction Text Linguistics, London, Longman.

Fox, B. A. (1986), Local patterns and general principles in cognitive processes: Anaphora in written and conversational English, Text (6)1, pp. 25-51.

Gabizon, R. (1970), “The Court's Burden of Justification”, [in Hebrew], Mishpatim Bet, pp.89-95.

Gavish, M. (1988), "Burden of Justification of Verdicts", [in Hebrew], Rivyon Yisraeli Lemisim, 17, pp.207-222.

Gitay, Y. (1991), Isaiah and his Audience, Assen/Maastricht: van Gorcum.

Greimas, A. J. \& Nef, F. (1977), Esaay sur la vie sentimentale des hippopotames, In: Van Dijk, T. A., and Petofi, J. S. (eds.) Grammars and Descriptions, Berlin, De Gruyter, pp.85-104. 
Horowitz, M. (1999), The Linguistic Side of the Coin [in Hebrew], Even Yehuda: Reches.

Hughes, R. E. \& Duhamel, P. A. (1962), Rhetoric, Englewood Cliffs, New-Jersey, Prentice-Hall Inc.

Kayam, O. (2011). Rhetoric on the Scales of Justice, Reference book on the linguistic-rhetoric of Supreme Court rulings [in Hebrew], Tel Aviv: Asef

Kayam, O. and Kaufman, H. (2011). "Rhetoric in Israeli Sports Journalism", HHE - Higher Hebrew Education Vol. 14, pp. 327-355.

Kayam, O. and Galily, Y. (2012). "Freedom of Speech? Israeli Supreme Court Ruling 606/93 - Kidum Initiative Inc. versus the Israel Broadcast Authority. A Rhetorical Language Analysis." Psychology of Language and Communication, Vol. 16. No. 1, pp 67-78.

Kayam, O. and Galily, Y. (2012). "The Language of Obama: A Rhetorical Analysis An examination of the emotive rhetorical devices appearing in Barack Obama's campaign speeches leading up to his inauguration." Submitted to the Journal of Issues in Discourse Analysis.

Kinneavy, J. L. (1971), A Theory of Discourse, New-Jersy, Prentice-Hall, Inc, Englewood Cliffs.

Levy, E. (1968), An Introduction to Legal Reasoning, The University of Chicago Press, Ltd London.

Malchin, Y. (1990), “The Question as Organizer of Thought and Director of Argument and Discussion" [in Hebrew], Dialogue, Jerusalem: Ariel Press.

Perlman, H. (1984), The Kingdom of Rhetoric, [in Hebrew], Hebrew University Jerusalem: Magnus Press.

Reboul, O. (1984), La rhétorique: Paris:PUF.

Roe B. D., et al. (1978), Reading Instruction in the Secondary School, Rand McNally, Chicago

Saral, T. (1991), Introduction to Discourse Analysis, [in Hebrew], Tel Aviv: Or-Am.

Shilo, G. (1996), Characteristics of Hebrew Theoretical Writing [in Hebrew], Ramat Gan: Bar-Ilan University Press.

Van Dijk, T. A \& Kintsch, W. (1983), Strategies of Discourse Comprehension, New York, Academic Press.

Weizman, E. (2000) "Irony in News Discourse" [in Hebrew]. In: Rodrigue-Schwarzwald, O., Blum-Kulka, S., and Olshtain, E. (eds.), Rafael Nir Jubilee Book: Studies in Communication, Linguistics and Language Teaching, Jerusalem, Carmel press, pp.237-248. 